\title{
Two new species of the genus Doryphorina Melichar, I 9 I 2 (Hemiptera, Fulgoromorpha, Dictyopharidae) from China
}

\author{
Yan-Li Zheng',2, Lin Yang', Xiang-Sheng Chen' \\ I The Provincial Key Laboratory for Agricultural Pest Management of Mountainous Region / Institute of \\ Entomology, Guizhou University, Guizhou Province, 550025 China 2 Guizhou Normal College, Guizhou \\ Province, 550018 China
}

Corresponding author: Xiang-Sheng Chen (chenxs3218@163.com)

Academic editor: Mike Wilson | Received 26 March 2014 | Accepted 6 June 2014 | Published 16 June 2014

http://zoobank.org/0483CCA8-D3C2-4D41-B2BE-3D78B43A3BDC

Citation: Zheng Y-L, Yang L, Chen X-S (2014) Two new species of the genus Doryphorina Melichar, 1912 (Hemiptera, Fulgoromorpha, Dictyopharidae) from China. ZooKeys 416: 31-39. doi: 10.3897/zookeys.416.7498

\begin{abstract}
Two new species of the genus Doryphorina Melichar, 1912, D. conglobatus Zheng, Yang \& Chen, sp. n. and D. guizhouensis Zheng, Yang \& Chen, sp. n., from China are described and illustrated. A key is given to identify all the known species of Doryphorina.
\end{abstract}

\section{Keywords}

Dictyopharid, distribution, Fulgoroidea, planthopper, taxonomy

\section{Introduction}

The dictyopharid planthopper genus Doryphorina (Hemiptera: Fulgoromorpha: Dictyopharidae) was established by Melichar (1912) based on a single species D. stali Melichar, from Sumatra. Later, Fennah (1978) described two subspecies D. stali minor and D. stali subdeflexa from Vietnam. Song and Liang (2013) revised and elevated the status of the two subspecies to species, the genus contained three species D. stali (Burma, Malaysia, Indonesia), D. minor (Vietnam, China: Guangxi, Hainan, Guangdong, Guizhou) and D. subdeflexa (Vietnam, China: Yunnan). In this paper, two new species D. conglobatus sp. n. and D. guizhouensis sp. n. from China, are described and illustrated. A key to identify all the known species of Doryphorina is given. 


\section{Material and methods}

Material examined here is deposited in the Institute of Entomology, Guizhou University, Guiyang, China (GUGC). Dry specimens were used for the observation, description and illustration. Genital segments of the examined specimens were macerated in boiling solution of $10 \% \mathrm{NaOH}$ and drawn from preparations in glycerin jelly under a Leica MZ12.5 stereomicroscope. Color pictures for adult habitus were obtained by a KEYENCE VHX-1000 system. Illustrations were scanned with Canon Cano Scan LiDE 200 and imported into Adobe Photoshop CS6 for labeling and plate composition. Terminology of morphology, genital characters and measurements follow Song and Liang (2013).

The following abbreviations are used in the text, BL: body length (from apex of cephalic process to tip of fore wings); HL: head length (from apex of cephalic process to base of eyes); HW: head width (including eyes); FWL: forewing length; GUGC: Guizhou University, Guiyang, China.

\section{Taxonomy}

\section{Doryphorina Melichar, 1912}

Figs 1-32

Doryphorina Melichar, 1912: 99. Type species: Doryphorina stali Melichar, 1912; by original designation.

Doryphorina: Schmidt 1915: 76; Distant 1916: 25; Schmidt 1928: 129; Metcalf 1946: 87; Fennah 1978: 254; Emeljanov 2011: 1125; Song and Liang 2013: 2.

Type species. Doryphorina stali Melichar, 1912 (original designation).

Diagnosis. For the relationships and a diagnosis of Doryphorina see Song and Liang (2013).

Distribution. Oriental region.

\section{Key to species of Doryphorina Melichar, 1912 based on males}

(Modified from Song and Liang 2013)

$1 \quad$ Vertex broad, lateral carinae nearly parallel; forewings without dull ochraceous spot near stigma ......................................................................... 2

- $\quad$ Vertex relatively narrow, broadest at base and apex, lateral carinae not parallel; forewings with a dull ochraceous spot near stigma.................................. 3

2 Dorsal apical lobes of phallobase with (Fig. 21) long and slender, with 3 long spines at base in dorsal view ...................................... D. conglobatus sp. $\mathbf{n}$.

- $\quad$ Dorsolateral apical lobes of phallobase directed laterally, with 2-3 long apical spines in dorsal view D. subdeflexa Fennah 
3 Cephalic process relatively short, with ratio length to length of pronotum and mesonotum combined less than or equal to 2.0 .......................................... 4

- Cephalic process relatively long, with ratio length to length of pronotum and

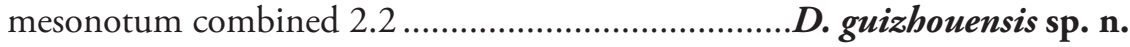

4 Gonostyles with upper process relatively short and broad; aedeagus with 2 pairs of apical lobes in ventral part .................................. D. minor Fennah

- $\quad$ Gonostyles with upper process distinctly slender and long; aedeagus with 1 pair of apical lobes in ventral part ................................... D. stali Melichar

\section{Doryphorina conglobatus Zheng, Yang \& Chen, sp. n.}

http://zoobank.org/CEEAC18E-B365-4511-B226-77BAE4CE903E

Figs $1-5,11-21$

Measurement. $\widehat{\jmath}$, BL: $16.2 \mathrm{~mm}$; HL: $4.6 \mathrm{~mm}$; HW: $1.7 \mathrm{~mm}$; FWL: $9.9 \mathrm{~mm}$.

Description. Body greenish-ochraceous, head and thorax with bluish green and reddish ochraceous markings.

Cephalic (Figs $1-3,11,13$ ) process relatively robust, a little upturned, with ratio length to length of pronotum and mesonotum combined 1.6. Vertex (Figs 1, 3, 11) broad, media carina weakly, only distinct at apex and base, ratio of length to width between eyes 5.2. Frons (Figs 5, 12) elongate, intermediate carinae sub-parallel, nearly approaching frontoclypeal suture; median carina complete, length 5.3 times long than width. Pronotum (Figs 1-3,11,13) distinctly shorter than mesonotum in the middle line, median carina distinct, lateral carina obscure, only slightly present at base. Mesonotum (Figs 1, 2, 11) tricarinate, lateral carinae straight, nearly parallel. Forewings (Figs 1, 14) hyaline, with ratio length to maximum width 3.3; stigma distinct, with 4-5 cells. Legs moderately elongate, fore femora not flattened and dilated, without spine; hind tibiae with 5 lateral black-tipped spines and 7 apical black-tipped teeth.

Male genitalia. Pygofer (Fig. 16) wider ventrally than dorsally, posterior margin with a blunt process, ventral margin depressed to accommodate anal tube. Anal tube (Fig.18) in dorsal view, with apex broader than base, the ventral margin with wrinkle. Gonostyles (Fig. 16) relatively small in lateral view, with apical margin not exceeding the apex of anal tube in lateral view, inner face with numerous setae in ventral view. Aedeagus (Fig. 19) with 1 pair of short endosomal processes, without extending from phallotheca. Phallobase (Figs 19-21) sclerotized and pigmented, with 2 pairs of apical membranous lobes: dorsal apical lobes (Fig. 19) long and slender, with 3 long spines at base; ventral lobes (Fig. 19) extending ventrally, with about 6 long spines each.

Female. Unknown.

Type material. Holotype đ̊, China: Shaanxi, Cuihuashan, 26 Aug. 2008, coll. Yujian Li (GUGC).

Distribution. China (Shaanxi). 

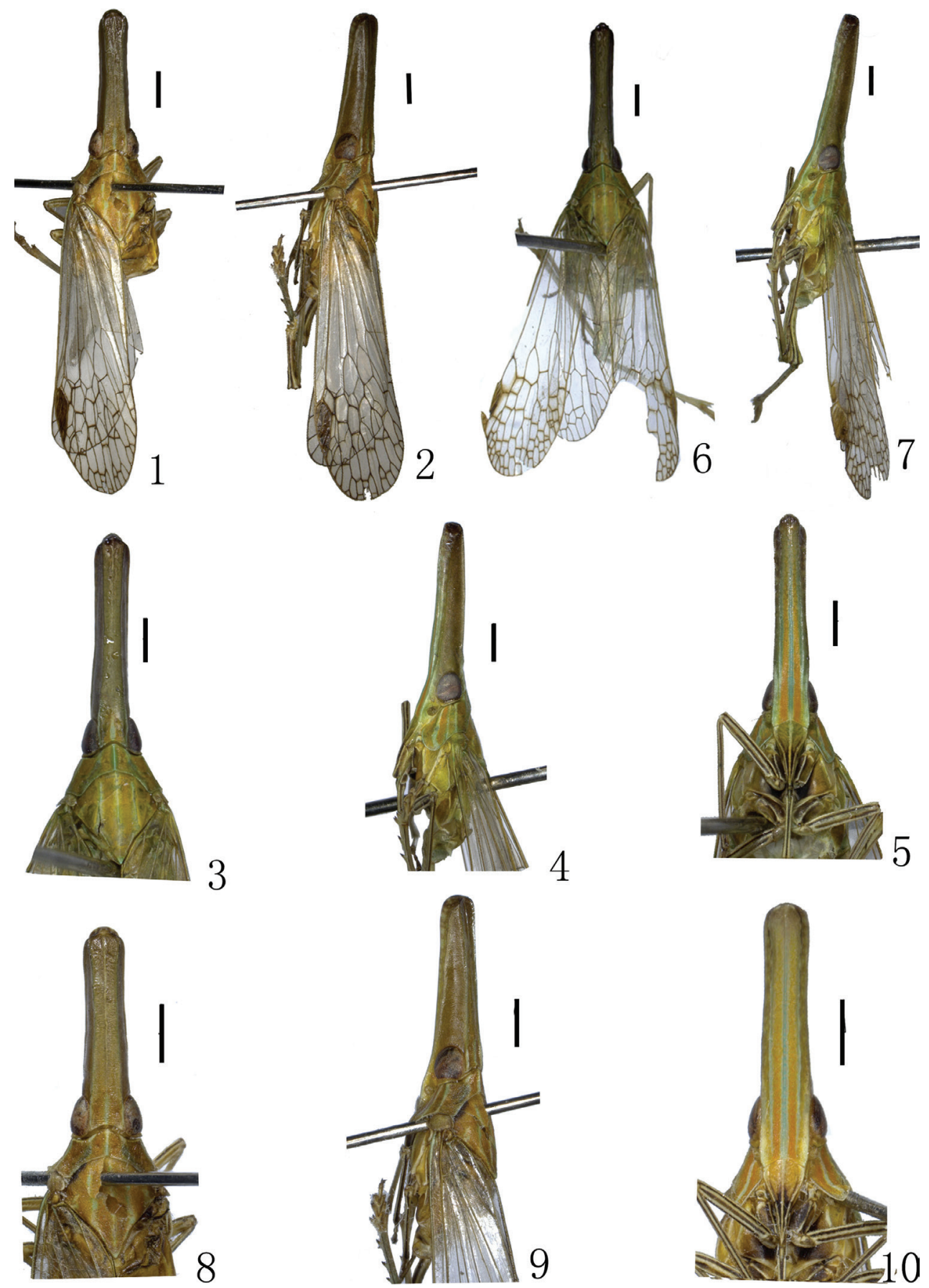

Figures I-10. I-5 Habitus of D. conglobatus sp. n. 6-10 D. guizhouensis sp. n. I, 6 dorsal view 2, 7 lartral view 3, 8 dorsal view of head, pronotum and mesonotum 4, 9 lateral view of head and pronotum 5, 10 ventral view of frons and clypeus. Scale bars: 1-10 $=1 \mathrm{~mm}$. 
Diagnosis. This species is similar to D. subdeflexa but can be distinguished from the later by phallobase with 2 pairs of apical membranous lobes, dorsal apical lobes (Fig. 19) long and slender, with 3 long spines at base (dorsal part with two pairs of dorsolateral apical lobes directed laterally, with 2-3 long apical spines in dorsal view in D. subdeflexa).

Etymology. This new species is derived from the Greek word "conglobatus", which indicate that the apical lobes of phallobase are connected.

\section{Doryphorina guizhouensis Zheng, Yang \& Chen, sp. n.} http://zoobank.org/A2B8FC58-606F-4F69-917C-90FCD0E8D7C8 Figs 6-10, 22-32

Measurement. ${ }^{\Uparrow}$, BL: 17.7-17.9 mm; HL: 5.4-5.6 mm; HW: 1.6-1.7 mm; FWL: $10.5-10.9 \mathrm{~mm}$.

Description. Body greenish or greenish-ochraceous, marked with bluish green and reddish ochraceous on head and thorax.

Cephalic (Figs 6-8, 22, 24) process relatively slender, a little upturned, with ratio length to length of pronotum and mesonotum combined 2.2. Vertex (Figs 6, 8, 22) broad, media carina weakly, only distinct at apex and base, ratio of length to width between eyes 6.3. Frons (Figs 10, 23) elongate, intermediate carinae sub-parallel, nearly approaching frontoclypeal suture; median carina complete, length 5.5 times long than wide. Pronotum (Figs 6-8, 22, 24) distinctly shorter than mesonotum medially, media carina distinct, lateral carina replaced by two pits. Mesonotum (Figs 6, 8, 22) tricarinate on disc, lateral carinae straight, nearly parallel. Forewings (Figs 6, 25) hyaline, with ratio length to maximum width 3.1; stigma distinct, with 4-5 cells. Legs moderately elongate, fore femora not flattened and dilated, without spine; hind tibiae with 5 lateral black-tipped spines and 7 apical black-tipped teeth.

Male genitalia. Pygofer (Fig. 27) wider ventrally than dorsally, posterior margin with a blunt process. Anal tube (Fig. 29) in dorsal view, the apex broader than base, the ratio of length to width about 1.8. Gonostyles (Fig. 27) relatively small in lateral view, shorter than the apex of anal tube in lateral view, inner face with numerous setae in ventral view. Aedeagus (Figs 30-32) with 1 pair of short endosomal processes, without extending from phallotheca. Phallobase (Figs 30-32) sclerotized and pigmented, with 2 pairs of apical membranous lobes: dorsal apical lobes (Fig. 31) long and slender, with 4 long apical spines each, ventral lobes (Fig. 31) with 2 pairs of apical lobes connected, not produced laterally, apex and base with about 16-19 long spines totally in ventral view.

Female. Unknown.

Type material. Holotype $\widehat{\delta}$, China: Guizhou, Congjiang, 24 Jul. 2005, coll. Deyan Ge. Paratype, 1ð̂, China: Guizhou, Libo, Aug. 1997, coll. Zizhong Li (both in GUGC).

Distribution. China (Guizhou). 

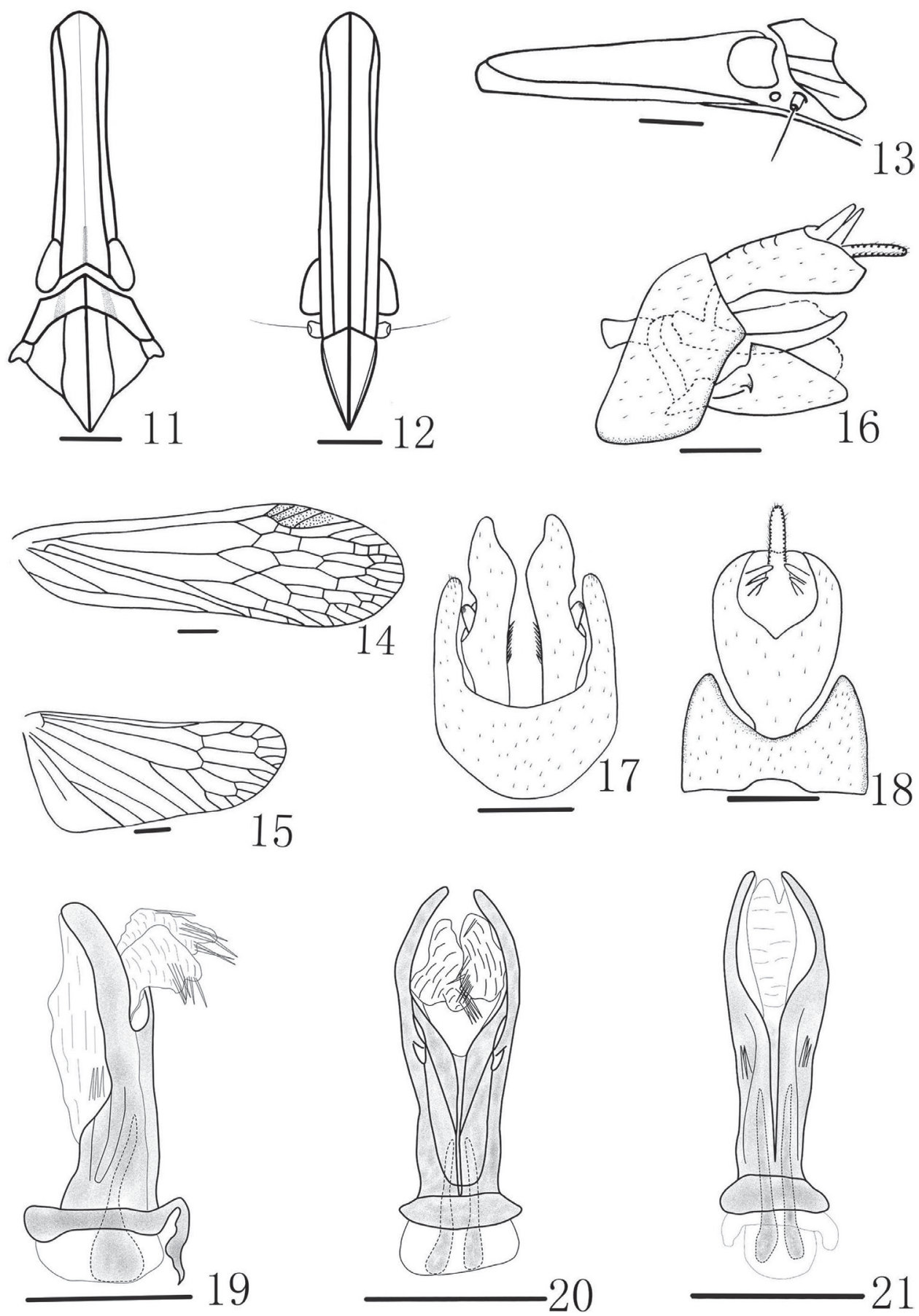

Figures II-2I. D. conglobatus sp. n. II Head and thorax, dorsal view $\mathbf{I} 2$ Frons and clypeus, ventral view 13 Head and pronotum, lateral view 14 Forewing 15 Hind Wing 16 Genitalia, lateral view 17 Pygofer and Gonostyles, ventral view 18 Pygofer and anal tube, dorsal view 19 Aedeagus, lateral view 20 Aedeagus, ventral view 2I Aedeagus, dorsal view. Scale bars: 11-15=1 mm, 11-16 = $0.5 \mathrm{~mm}$. 

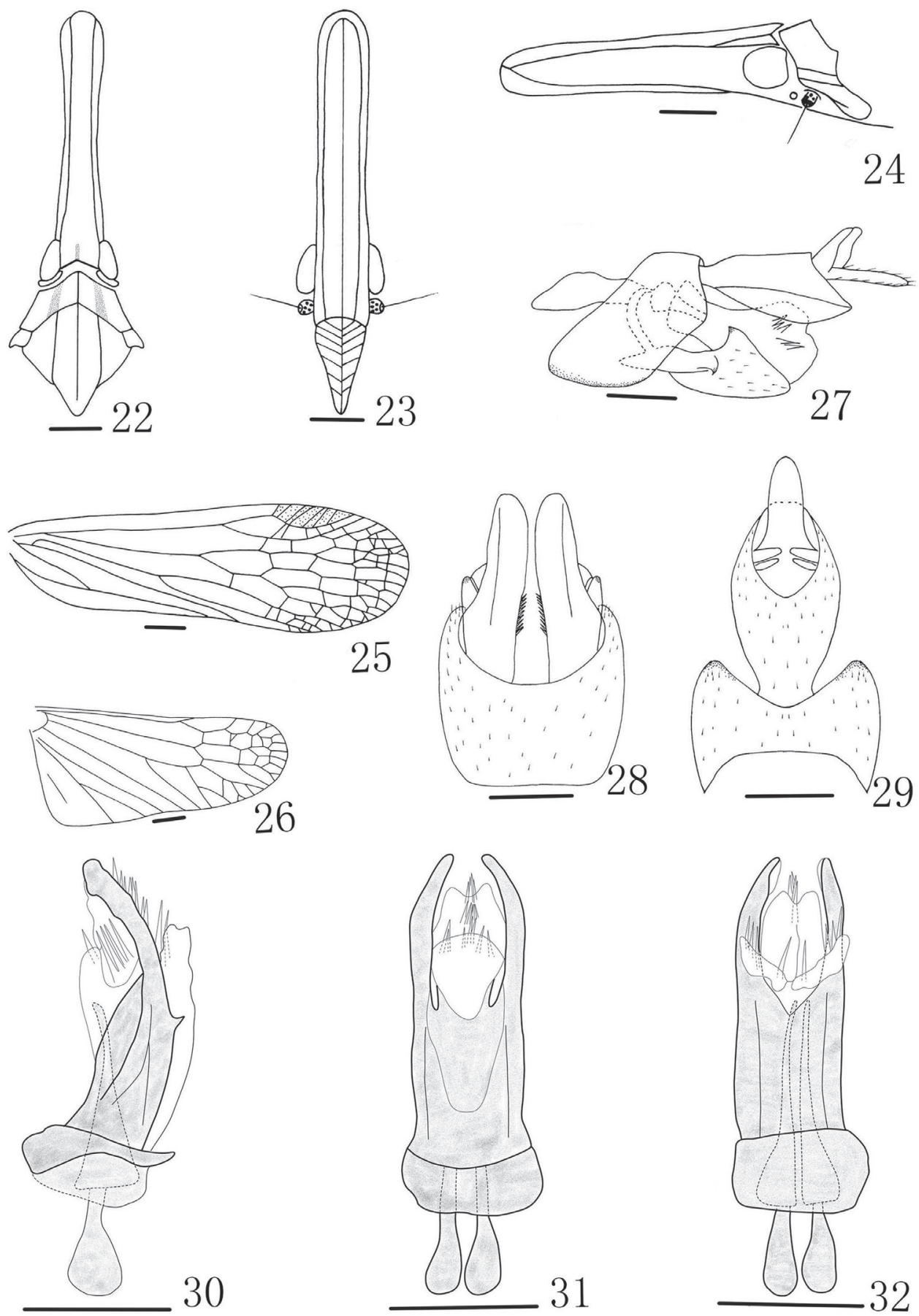

Figures 22-32. D. guizhouensis sp. n. 22 Head and thorax, dorsal view 23 Frons and clypeus, ventral view 24 Head and pronotum, lateral view 25 Forewing 26 Hind Wing 27 Genitalia, lateral view 28 Pygofer and Gonostyles, ventral view 29 Pygofer and anal tube, dorsal view $\mathbf{3 0}$ Aedeagus, lateral view 3I Aedeagus, ventral view 32 Aedeagus, dorsal view. Scale bars: 22-26 = $1 \mathrm{~mm}, \mathbf{2 7 - 3 2}=0.5 \mathrm{~mm}$. 
Diagnosis. This species is similar to $D$. minor, but can be distinguished from the later by phallobase ventral lobes (Fig. 31) with 2 pairs of apical lobes connected, not produced laterally, apex and base with about 16-19 long spines totally in ventral view (ventral part with two pairs of $\mathrm{V}$-shaped elongate apical lobes, directed laterally and ventrally, each with 4-5 long spines in ventral view in D. minor).

Etymology. This new species name refers to the type locality, Guizhou Province.

\section{Discussion}

D. conglobatus sp. $\mathrm{n}$. is similar to D. subdeflexa but can be distinguished from the later by phallobase lobes; $D$. guizhouensis sp. n. is similar to $D$. minor and $D$. stali but can be distinguished from $D$. minor by phallobase ventral lobes (Fig. 31); and can be distinguish from $D$. stali by phallobase dorsal lobes (Fig. 32); D. conglobatus sp. n. can be distinguished from $D$. guizhouensis sp. n. and D. minor, D. stali by the relatively robust cephalic process; the forewings without dull ochraceous spot near stigma. So, external features and phallobase lobes play an important role to identify of all male species in the genus.

The new species and all described species all distributed Oriental region. So far, this genus belongs to Oriental region.

\section{Acknowledgements}

We are grateful to Prof. Zi-Zhong Li (Institute of Entomology, Guizhou University, Guiyang, Guizhou, China) for collecting valuable specimens. This work was supported by the National Natural Science Foundation of China (No. 31060290, 31093430, 31160163) and the International Science and Technology Cooperation Program of Guizhou (20107005).

\section{References}

Distant WL (1916) The Fauna of British India, including Ceylon and Burma. Rhynhota Vol. VI (Heteroptera-Homoptera). Taylor \& Francis, London, 248.

Emeljanov AF (2011) Improved tribal delimitation of the subfamily Dictyopharinae and description of new genera and new species (Homoptera, Fulgoroidea, Dictyopharidae). Entomologicheskoe Obozrenie 90: 299-328. [English translation in Entomological Review 91: 1122-1145, 2011]

Fennah RG (1978) Fulgoroidea (Homoptera) from Vietnam. Annales Zoologici 34(9): 207-279. Schmidt E (1915) Die Dictyopharinen des Stettiner Museums (HemipteraHomoptera). Entomologische Zeitung. Herausgegeben von dem entomologischen Vereine zu Stettin 76: 345-358. 
Schmidt E (1928) Die Zikaden des Buitenzorger Museums (Hemipt.-Homopt.). I. Treubia 10: $107-144$.

Song ZS, Liang AP (2013) Review of the genus Doryphorina Melichar, 1912 (Hemiptera: Fulgoromorpha: Dictyopharidae). Journal of Insect Biodiversity 1(7): 1-12. doi: 10.12976/ jib/2013.1.7

Melichar L (1912) Monographie der Dictyophorinen (Homoptera). Abhandlungen der K. K. Zoologisch-Botanischen Gesellschaft in Wien 7(1): 1-221.

Metcalf ZP (1946) General catalogue of the Hemiptera, Fasc. IV. Fulgoroidea, Part 8 Dictyopharidae. Smith College, Northampton, MASS, 246 pp. 